\title{
The decline in paediatric malaria admissions on the coast of Kenya
} Emelda A Okiro*1, Simon I Hay ${ }^{1,2}$, Priscilla W Gikandi1, Shahnaaz K Sharif3, Abdisalan M Noor ${ }^{1}$, Norbert Peshu ${ }^{4}$, Kevin Marsh ${ }^{4,5}$ and Robert W Snow ${ }^{1,5}$

\author{
Address: ${ }^{1}$ Malaria Public Health \& Epidemiology Group, Centre for Geographic Medicine Research - Coast, Kenya Medical Research Institute/ \\ Wellcome Trust Research Programme, P.O. Box 43640, 00100 GPO, Nairobi, Kenya, ${ }^{2}$ Spatial Ecology and Epidemiology Group, Department of \\ Zoology, University of Oxford, Tinbergen Building, South Parks Road, Oxford, OX1 3PS, UK, ${ }^{3}$ Ministry of Health, Afya House, Cathedral Road, \\ P.O. Box 30016, 00100 GPO, Nairobi, Kenya, ${ }^{4}$ Centre for Geographic Medicine - Coast, Kenya Medical Research Institute, P.O. Box 230, Kilifi, \\ Kenya and ${ }^{5}$ Centre for Tropical Medicine, University of Oxford, John Radcliffe Hospital, Headington, Oxford, OX3 9DU, UK \\ Email: Emelda A Okiro* - eokiro@nairobi.kemri-wellcome.org; Simon I Hay - shay@nairobi.kemri-wellcome.org; \\ Priscilla W Gikandi - pgikandi@nairobi.kemri-wellcome.org; Shahnaaz K Sharif - sksharif@africaonline.co.ke; \\ Abdisalan M Noor - anoor@nairobi.kemri-wellcome.org; Norbert Peshu - npeshu@kilifi.kemri-wellcome.org; \\ Kevin Marsh - kmarsh@kilifi.kemri-wellcome.org; Robert W Snow - rsnow@nairobi.kemri-wellcome.org \\ * Corresponding author
}

\section{Published: I5 November 2007}

Malaria Journal 2007, 6:15I doi:10.1 |86/|475-2875-6-I5I
Received: 27 July 2007

Accepted: 15 November 2007

This article is available from: http://www.malariajournal.com/content/6/1/15I

(C) 2007 Okiro et al; licensee BioMed Central Ltd.

This is an Open Access article distributed under the terms of the Creative Commons Attribution License (http://creativecommons.org/licenses/by/2.0), which permits unrestricted use, distribution, and reproduction in any medium, provided the original work is properly cited.

\begin{abstract}
Background: There is only limited information on the health impact of expanded coverage of malaria control and preventative strategies in Africa.

Methods: Paediatric admission data were assembled over 8.25 years from three District Hospitals; Kilifi, Msambweni and Malindi, situated along the Kenyan Coast. Trends in monthly malaria admissions between January 1999 and March 2007 were analysed using several time-series models that adjusted for monthly non-malaria admission rates and the seasonality and trends in rainfall.

Results: Since January 1999 paediatric malaria admissions have significantly declined at all hospitals. This trend was observed against a background of rising or constant non-malaria admissions and unaffected by long-term rainfall throughout the surveillance period. By March 2007 the estimated proportional decline in malaria cases was $63 \%$ in Kilifi, $53 \%$ in Kwale and $28 \%$ in Malindi. Time-series models strongly suggest that the observed decline in malaria admissions was a result of malariaspecific control efforts in the hospital catchment areas.

Conclusion: This study provides evidence of a changing disease burden on the Kenyan coast and that the most parsimonious explanation is an expansion in the coverage of interventions such as the use of insecticide-treated nets and the availability of anti-malarial medicines. While specific attribution to intervention coverage cannot be computed what is clear is that this area of Kenya is experiencing a malaria epidemiological transition.
\end{abstract}




\section{Background}

Since the inception of the Roll Back Malaria (RBM) movement in 1996 [1], billions of health dollars have been committed by the international donor community to reduce the burden of malaria in Africa [2], estimated to be over a million deaths directly due to Plasmodium falciparum annually [3]. However there are remarkably few documentations of changes in disease burden associated with increases in access and use of interventions funded by new international donor agency money.

In Kenya the expansion of coverage of both ITN and effective ACT therapy (artemether-lumefanthrine) has occurred very recently. Between 2004 and 2005 ITN coverage among children aged less than five years rose from $7 \%$ to $24 \%$ and by the end of 2006 had risen to $67 \%$ coverage [4]. Despite delays in implementing the revised drug policy supporting the use of AL [5], over $85 \%$ of rural clinics had AL in stock between August and December 2006 [6]. Paediatric admission time-series from three Kenyan hospitals were assembled to explore the impact of parallel changes in intervention coverage and malaria disease burden.

\section{Methods}

\section{Paediatric admission data}

Three district hospitals were selected purposively along a $170 \mathrm{~km}$ stretch of the Kenyan coast at Malindi, Kilifi and Msambweni (located in Kwale district). They are located in three different districts of Coast Province, and all serve populations who share similar climatic, ecological and economic characteristics (Figure 1).
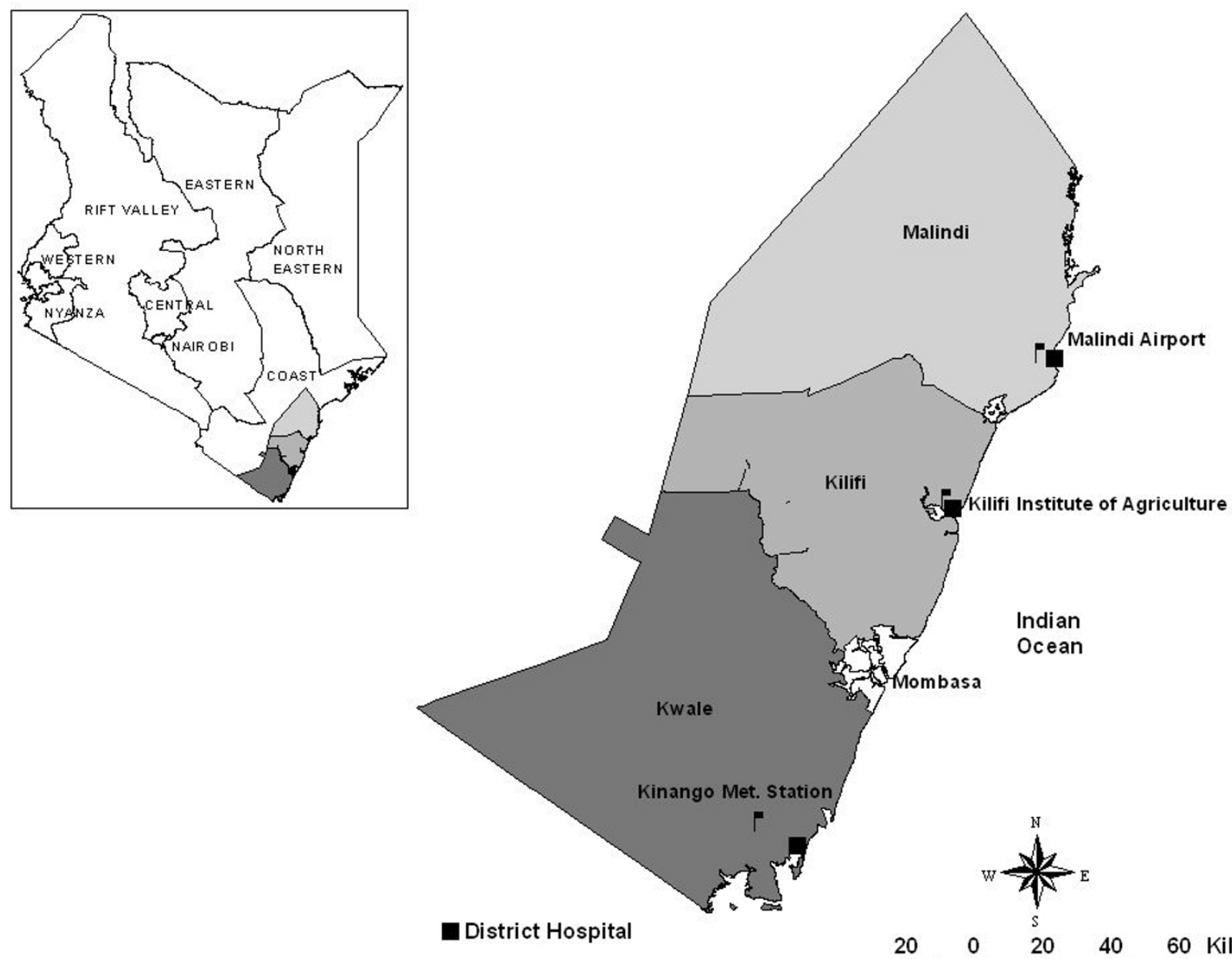

District Hospital

Figure I

Map showing the three study districts and the location of the metrological station in relation to the hospital facility. Inset is a map of Kenya showing location of three districts. 
Paediatric ward in-patient registers at Malindi and Msambweni were identified for all months from January 1999 to March 2007. These were arranged serially to check whether these represented a continuous, uninterrupted series. Each admission entry in the registers was recorded on a separate tally sheet indicating the month of admission, whether a primary working diagnosis of malaria had been defined for the child, whether the admission diagnosis was not malaria and whether the child had survived admission. Separately, hospital death certificates were reviewed for the same period to identify any paediatric deaths that may have not been recorded in the admission ward books. All paediatric admissions were assumed to be aged between birth and 15 years. Individual register entries were not reconciled with patient notes and thus we have assumed that the admission diagnosis remained the clinical management diagnosis and it is used here as the diagnosis of analysis. The reliability of slide confirmed malaria diagnosis at admission was not validated from hospital or laboratory records as these procedures are variously performed in most Kenyan district hospitals [7] and results are rarely used to refine a diagnosis [8-10].

At Kilifi district hospital a sophisticated paediatric ward surveillance system has been in situ since 1989 to form the basis of a series of clinical studies on the pathogenesis of malaria, pneumonia, malnutrition and neonatal illness [11-14]. Clinical and laboratory coverage is provided 24 hours each day throughout the year. Demographic details and clinical histories are recorded on every admission and a finger prick blood sample taken for malaria parasitology and basic haematology. Following a clinical examination at admission further clinical and laboratory investigations are undertaken as indicated. Clinical and laboratory findings, clinical progress and response to therapy were reviewed at discharge to derive a primary diagnosis and recorded on a standard admission proforma later entered onto a centralized database. Data for the present study were reassembled for the period January 1999 through to March 2007 and summarized by month as a discharge diagnosis of malaria or non-malaria for all admissions aged between birth and 15 years of age.

\section{Ancillary data}

Seasonal patterns of malaria hospitalization are related to monthly rainfall precipitations along the Kenyan coast [15] and relate principally to the population dynamics of the dominant vector species [16]. Monthly rainfall data in decimal $\mathrm{mm}$ were obtained from meteorological offices located $3 \mathrm{~km}$ (Malindi), $2 \mathrm{~km}$ (Kilifi) and $25 \mathrm{~km}$ (Msambweni) from the respective district hospitals and were complete across the same time-period as the paediatric ward surveillance (Figure 1). The Kenyan coast is an area where sporogony in the vector population and hence malaria transmission, is not limited by ambient tempera- ture and therefore temperature data were not included in the analysis.

Natural population growth over the 8.25 observation years is likely to have affected the size of population accessing these three hospitals. Precise rates of admission adjusted for monthly denominator size were not possible for the hospitals as the catchment for these services cannot be rigorously defined over time [17]. Non-malaria admissions data were also collected, however, to help calibrate for population and other issues affecting hospital usage.

\section{Data analysis}

Analysis was undertaken using STATA version 9.2 (Statacorp 2003, College Station, USA). Hospital admission data obtained over the 99 months of surveillance between January 1999 and March 2007. Malaria admission case totals were assembled chronologically by admission month and non-malaria admissions similarly assessed for comparison purposes. They were examined with time series analysis that used malaria admission cases as the main outcome.

Smoothing techniques (moving averages) were used to filter short-term annual fluctuations and thus highlight longer-term trends present in the each of the data series. Malaria, non-malaria and rainfall, time series data from Kilifi, Kwale and Malindi were subject to 13-point moving average to aid visual interpretation of trends. Deviations in monthly rainfall were also examined by comparing monthly values of these parameters obtained during the study period with synoptic mean values computed from the 8.25 years of surveillance. The disparity between long term values and current values was referred to as an anomaly and had either positive or negative values.

A regression model expressing malaria cases as a linear combination of non-malaria cases and rainfall was used to test for trend. The non-malaria cases and rainfall allow trend statistics to be presented that are "aware" of other potential longitudinal influences on malaria admissions. A continuous variable indicating the time in months from the start of the observation period was included in the regression model. The coefficient of time in the model estimates the trend in the series (i.e. the month-to-month change in the number of admission cases). A P-value of < 0.05 was considered significant. There were strong seasonal fluctuations observed for malaria admissions, with a higher proportion of admissions recorded in the rainy season than in the dry season. To control for the confounding effect of seasonality on the trend, seasonal effects were included in the regression model by the use of indicator terms (dummy variables). The 11 dummy variables are constructed as time series with the value one for observations falling in a given month and zero when not. 
The final month was used as the baseline for comparison. There are thus 11 potential intercepts generated depending on the choice of baseline month for comparison; we elected to plot and discuss the intercept and trend that had the maximum correlation with the 13-point moving average. These analyses were conducted separately for each district.

A key assumption when using ordinary least squares regression is that the model residuals are independent [18] and this is often violated by longitudinal data [19]. In the presence of autocorrelation standard errors of parameter estimates are underestimated resulting in an overestimation of significance. The Durbin-Watson statistic was hence used to test for serial autocorrelation [20]. Serial correlation was found in all malaria admission data series (results not shown) indicating that correction was necessary. An analysis of autocorrelation and the sample partial autocorrelation function of deseasonalised data $[19,21]$ showed that a correction of this serial correlation with a lag of two months was optimal. Newey-West standard errors $[21,22]$ with a lag of two months were therefore used to correct for autocorrelation and potential heteroscedasticity.

\section{Results}

\section{Descriptions of the data}

Longitudinal data was obtained from all the hospitals for the period starting January 1999 to March 2007. During the 8.25 years of surveillance there were a total of 76,101 paediatric admissions: 41,715 admissions in Kilifi, 13,492 in Kwale and 20,894 admissions in Malindi. A total of $34 \%$ of the total admissions had a diagnosis of malaria; 32\% (13,919) in Kilifi, 40\% $(5,361)$ in Kwale, and $36 \%(7,498)$ in Malindi.

The annual number of malaria admissions declined with time (Table 1) in all three locations. In 1999 the proportion of admissions due to malaria was $46 \%$ in Kilifi, 51\% in Kwale and 45\% in Malindi. In 2006, seven years after the start of surveillance, this proportion had declined to $13 \%$ in Kilifi, 26\% in Kwale and 24\% in Malindi. The proportional decline was greatest in Kilifi (-72\%) and lowest in Malindi $(-38 \%)$. Conversely, within the same period, the proportion of admissions diagnosed as non-malaria increased (Table 1). The largest proportional increase in non-malaria cases was observed in Malindi at 64\% while the lowest increase was recorded in Kwale 15\%. The proportional increase in non-malaria admissions in Kilifi was $52 \%$.

\section{Seasonally adjusted linear regression analysis of admissions}

Malaria admissions in all three study sites were observed to show significant downward trends (Table 1). When adjusting for the increases in non-malaria admissions the decreasing trend in malaria admissions became more pronounced in Kilifi and Malindi (Table 2; $\mathrm{P}<0.001$ ). By March 2007 the estimated proportional decline in malaria cases was $63 \%$ in Kilifi, $53 \%$ in Kwale and $28 \%$ in Malindi. Values of the intercepts and coefficients of trends are detailed in Table 1 and shown in Figure 2 - left panel. Including rainfall as an additional covariate had little effect on the intercept and slope of the trends observed so that the trends were indistinguishable on Figure 2 (results not shown).

Table I: Trends in paediatric admissions during the period Januaryl 999 to March 2007 at three sites on the Kenyan coast.

\begin{tabular}{|c|c|c|c|c|c|}
\hline & 1999 & 2006 & Change (\%) & Intercept (95\% confidence interval) & Trend (95\% confidence interval) \\
\hline \multicolumn{6}{|c|}{ Malaria Admissions } \\
\hline Total across sites & 4611 & 1796 & -61 & & \\
\hline Kilifi & 2395 & 660 & -72 & $259.57(155.64,363.49)$ & $-1.67 \dagger(-2.29,-1.05)$ \\
\hline Kwale & 1053 & 418 & -60 & $80.12(58.88,101.35)$ & $-0.43+(-0.65,-0.21)$ \\
\hline Malindi & 1163 & 718 & -38 & $119.15(84.00,154.31)$ & $-0.33^{+}(-0.59,-0.08)$ \\
\hline \multicolumn{6}{|c|}{ Non-Malaria Admissions } \\
\hline Total across sites & 5215 & 7724 & 48 & & \\
\hline Kilifi & 2791 & 4243 & 52 & $236.72(194.95,278.50)$ & $1.37 \dagger(0.92,1.81)$ \\
\hline Kwale & 1022 & 1175 & 15 & $73.47(50.16,96.78)$ & $-0.01 \ddagger(-0.31,0.29)$ \\
\hline Malindi & 1402 & 2306 & 64 & $79.45(57.55,101.35)$ & $0.91+(0.60,1.23)$ \\
\hline \multicolumn{6}{|l|}{ Rainfall } \\
\hline Kilifi & 1197.7 & 2099.7 & 75 & $81.98(38.27,125.58)$ & $0.10 \ddagger(-0.65,0.85)$ \\
\hline Kwale & |59|.| & 1910.2 & 20 & $48.96(4.55,93.37)$ & $-0.04 \ddagger(-0.89,0.80)$ \\
\hline Malindi & 1020.7 & 1505.2 & 47 & $84.32(52.82,115.83)$ & $0.02 \ddagger(-0.40,0.44)$ \\
\hline
\end{tabular}

$\dagger_{p}<0.001$. $¥$ Not significant $(p>0.05)$. 
Table 2: Trend of monthly malaria admissions during period the period January 1999 to March 2007 at three sites on the Kenyan coast.

\begin{tabular}{|c|c|c|c|c|c|c|}
\hline \multirow[t]{2}{*}{ Parameters } & \multirow[t]{2}{*}{ coefficient } & \multirow[t]{2}{*}{ NW SE* } & \multirow[t]{2}{*}{ t-stat } & \multirow[t]{2}{*}{ P-value } & \multicolumn{2}{|c|}{$95 \%$ confidence interval } \\
\hline & & & & & & \\
\hline Intercept & 145.887 & 71.50 & 2.04 & 0.044 & 3.69 & 288.08 \\
\hline Trend & -2.320 & 0.40 & -5.80 & 0.000 & -3.12 & -1.52 \\
\hline Non-mal cases & 0.478 & 0.19 & 2.47 & 0.016 & 0.09 & 0.86 \\
\hline Rainfall & 0.094 & 0.05 & 1.92 & 0.058 & 0.00 & 0.19 \\
\hline \multicolumn{7}{|l|}{ Kwale } \\
\hline Intercept & 52.933 & 12.62 & 4.20 & 0.000 & 27.84 & 78.02 \\
\hline Trend & -0.425 & 0.10 & -4.19 & 0.000 & -0.63 & -0.22 \\
\hline Non-mal cases & 0.377 & 0.08 & 4.64 & 0.000 & 0.22 & 0.54 \\
\hline Rainfall & -0.018 & 0.02 & -0.78 & 0.435 & -0.06 & 0.03 \\
\hline \multicolumn{7}{|l|}{ Malindi } \\
\hline Intercept & 95.395 & 19.54 & 4.88 & 0.000 & 56.53 & 134.26 \\
\hline Trend & -0.574 & 0.15 & -3.78 & 0.000 & -0.88 & -0.27 \\
\hline Non-mal cases & 0.262 & 0.14 & 1.84 & 0.069 & -0.02 & 0.55 \\
\hline Rainfall & 0.007 & 0.07 & 0.11 & 0.910 & -0.12 & 0.14 \\
\hline
\end{tabular}

*NWSE: Newey-West standard errors.

Significant $(\mathrm{P}<0.001)$ upward trends in non-malaria admission cases were shown in both the Kilifi and Malindi hospitals over the study period (Table 1). There was no statistically significant difference in Kwale. By March 2007, non-malaria admission cases in Kilifi and Malindi were estimated to have increased by $56 \%$ and over $100 \%$ respectively (Figure 2 - right panel) while remaining relatively consistent in Kwale. Again including rainfall as an additional covariate had little effect on the intercept and slope of the trends observed (results not shown).

\section{Seasonally adjusted linear regression analysis of rainfall and anomalies}

The trend in rainfall patterns remained relatively stable during the 8.25 years of surveillance. There was no evidence of consistent changes in rainfall patterns over the period with no significant synoptic trends identified in any of the three study sites (Table 1, Figure 3 - left panel). The anomaly analyses show that during the period 20042005, monthly rainfall in all the three study sites was lower on average than the computed long term means (Figure 3 - right panel). Thus there were no notably drier years except during this period. This was followed by considerable increase in rainfall in 2006 in all the study sites.

\section{Discussion}

Between January 1999 and March 2007 (8.25 years) admissions due to malaria have systematically declined at three sites along the Kenyan coast. These declines were examined in relation to possible changes in overall hospital utilization by a naturally growing paediatric population size and within and between year variations in rainfall. The fact that the significant decline in malaria admissions occurred against a significant rise in nonmalaria admissions in Kilifi and Malindi and remained unchanged at Kwale during the surveillance period (Figure 1, right panel) suggests that the declining admissions due to malaria were specific to malaria. It could be argued that an increase in non-malaria cases might be attributed to a changing diagnostic pattern over the surveillance period with fewer misclassifications or more doctors accepting as true malaria test results. This cannot be ruled out at Malindi or Kwale but at Kilifi standardized diagnostic practices have applied to all paediatric admissions throughout the entire surveillance period and thus changes in the pattern of diagnosis seem an unlikely explanation for the trends observed.

The monthly incidence of malaria is coupled to seasonal rainfall patterns on the Kenyan coast. The addition of rainfall as a covariate to the model had no effect on the slope or intercept of seasonally corrected trend lines because rainfall patterns were shown to have remained relatively constant during the observation period with no significant increasing or decreasing trends observed in any of the study sites. Attributing the long-term reduction in malaria cases to a constant change in rainfall is implausible as there was no evidence of a substantial decline in rainfall except for the anomaly recorded in 2004/5, where rainfall was lower on average than that expected (Figure 3, right panel). This was however followed by a considerable substantial increase in amount of rainfall recorded in 2006. Despite this there was no associated increase in malaria admissions observed in 2006 or early 2007. 

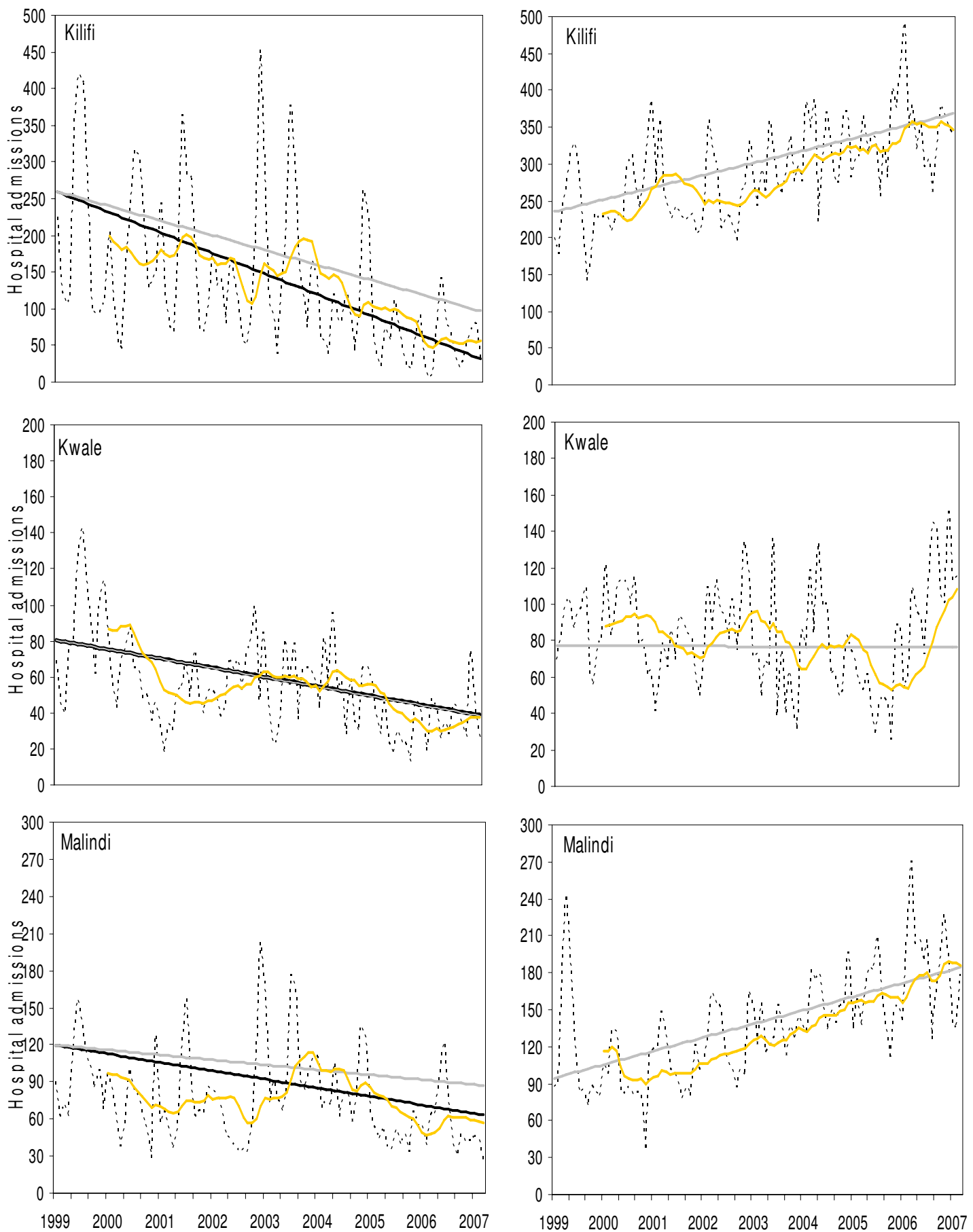

\section{Figure 2}

Admissions by month for the period January 1999 to March 2007 at three sites on the Kenyan coast. The top row is Kilifi, the middle row Kwale and the bottom Malindi. The graphs show malaria admissions (left column) and non-malaria admissions (right column) as dashed lines. The yellow solid line is a I3-point moving average applied to filter seasonal variation and highlight the long-term movements in the data. The two solid tone lines illustrate the change in admissions adjusted for seasonality (light grey) and seasonality, rainfall and non-malaria admissions (black). The intercept was chosen (from the potential II) based on the maximal correlation with the I3-point m.a. 

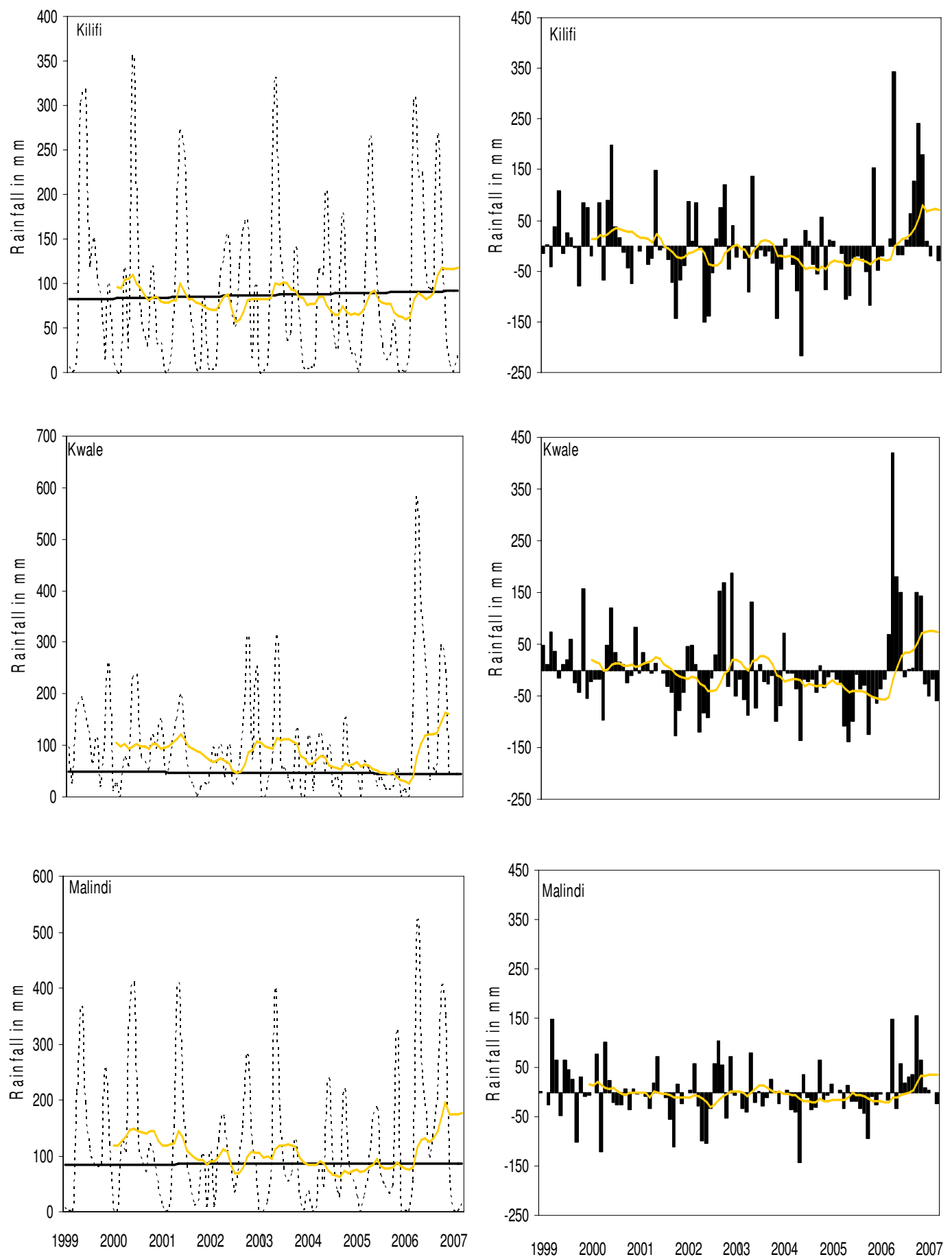

Figure 3

Rainfall per month for the period January 1999 to March 2007 at three sites on the Kenyan coast. The top row is Kilifi, the middle row Kwale and the bottom Malindi. The graphs in the left column show the monthly rainfall in $\mathrm{mm}$ as dashed lines. The yellow solid line is a 13 -point moving average applied to filter seasonal variation and highlight the long-term movements in the data. Trends corrected for seasonality are shown in black. The rainfall expressed as anomalies relative to $1999-2007$ monthly mean for each site are shown in the middle column. The 13-point moving average is again also shown. The intercept was chosen (from the potential II) based on the maximal correlation with the I3-point m.a. 
The use of three different hospital admission series increases the external validity of a single observation from one hospital. We consider the data from Kilifi as the diagnostic gold standard based on the use of microscopy and a discharge diagnosis supported by review of clinical notes. Using this as our point of reference, external validity of this result is provided by data from Msambweni (Kwale) and Malindi. It is reassuring then that a consistent declining pattern in malaria admission is maintained across all study sites lending weight to the strength of the findings. By 2006, annual malaria admissions had decreased by an average of 57\% compared to 1999 across all sites.

There are several possible factors that might explain these observations and are considered as plausibility arguments, as proposed by Habicht [23] and Victora [24], rather than measurable correlates. The most notable programmatic change over the 8.25 years of surveillance has been the increasing use of ITNs [4]. We have assembled a population adjusted estimate of the per capita ITN distri- bution patterns between 1999 and 2007 across the three districts combined (Figure 4). At the start of the observation period ITN distribution in all the three study sites was negligible. During the period 2001-2004, there was a steady increase in the cumulative per capita ITN distribution (Figure 4). One year after initiation of a retail sector programme (beginning of 2003), cumulative ITN distribution was estimated to be $3 \%$ per capita across the three districts. By December 2004, three months after the inception of an MCH clinic sales programme, cumulative ITN distribution was over 13 nets per 100 people. The largest increase occurred in September 2006 during the mass distribution campaign from an estimated 0.34 nets per capita in August 2006 to 0.49 nets per capita by September 2006. Extending the surveillance from 2006 into March 2007 corresponds to a period of highest ITN "coverage", implementation of a new effective first line treatment policy and increasing rainfall. Even so the anomaly in malaria admissions recorded was greatest during this period with an average of -79 in Kilifi, -34 in Malindi and -14 in Kwale. It should, however, be recognized that the decrease

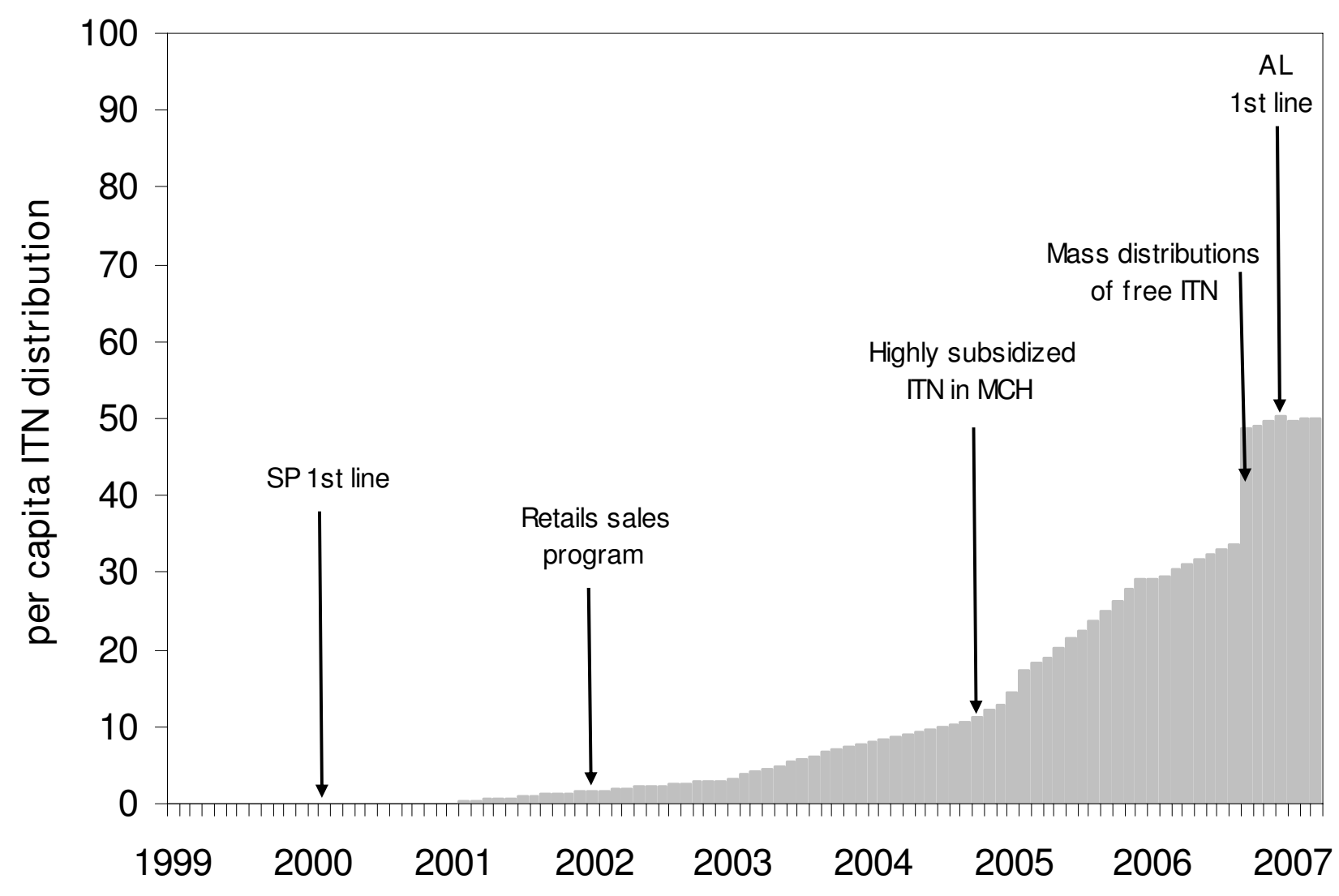

Figure 4

Cumulative monthly ITN distribution volumes expressed per capita across the three districts of Malindi, Kilifi and Kwale. 
in malaria cases started before the major expansion of prevention coverage in 2006, reasons for this remain unclear.

Data on the serial use of prompt, effective antimalarial treatment in each of the three districts was not possible to assemble. However a semi-qualitative, temporal description of drug efficacy is possible in accordance with national first line recommendations for treatment between 1999 and 2007. Between January 1999 and early 2000 chloroquine was still the only available antimalarial in government clinics despite wide-spread resistance documented on the coast [25]. Between mid-2000 and April 2006 sulphadoxine-pyrimethamine (SP) was the nationally recommended first line drug available in most government clinics and drug efficacy declined rapidly over this period in Kilifi and Kwale until most studies showed at least 25\% failure rates when undertaken after 2002 $[26,27]$. The policy was changed in April 2004 to artemether-lumefathrine (AL) but was not effectively implemented until December 2006 [5]. The efficacy of AL was defined in Kilifi as in excess of $94 \%$ in 2002-2003 [28]. Patient access to antimalarials within 48 hours of onset of symptoms has been documented in Kwale district in 2001 (15\%) and 2006 (17\%) ([29]; unpublished data), both representing very low estimates of prompt access and we assume not dissimilar to anticipated access figures for Kilifi and Malindi districts during the same period. However, the widespread availability of even sub-efficacious SP over-the-counter from 2000 onwards in Kwale [30,31] and Kilifi [32] may have had a suppressive effect on clinical disease risks operating similar to strategies prompting intermittent presumptive treatment in young children [33].

The use of hospital data provides a useful indicator of the long-term and short-term impact of scaling-up malaria interventions. It is not possible to definitely attribute carefully controlled and adjusted changes in malaria admission rates to expanded coverage of preventative and curative interventions; however these seem to be the most parsimonious explanations for the observations reported here along the Kenyan coast.

\section{Authors' contributions}

EA Okiro assembled all the hospital data, developed the analytical models and wrote the manuscript; SI Hay provided technical support for the time-series models and contributed to the drafting of the manuscript; PW Gikandi supervised the collection of all the hospital data since 1999; SK Sharif was the Provincial Medical Officer for Coast province between 1999 and 2005 responsible for the delivery of services and collection of health information and contributed to the final draft of the manuscript; AM Noor was responsible for the assembly of the ITN data in each district and contributed the final manuscript; $\mathrm{N}$
Peshu and K Marsh were overall responsible for the data provided by Kilifi district hospital and contributed to earlier drafts of the manuscript. RW Snow was responsible for the conception and continued funding of the project and its overall scientific management, analysis, interpretation and preparation of the final manuscript. All authors read and approved the final manuscript.

\section{Appendix}

Table 1

Footnote: The intercept refers to the seasonally adjusted level of malaria and non-malaria cases and rainfall at the start of the observation period. Models for malaria and non-malaria included a covariate for rainfall. The regressions were performed with Newey-West standard errors with a lag of two months for models with malaria and non-malaria case outcomes and a lag of one month for models with rainfall.

Table 2

Footnote: The intercept refers to the seasonally adjusted level of malaria cases at the start of the observation period. Models included a covariate for non-malaria cases and rainfall. The regression was performed with Newey-West standard errors with a lag of two months for models with malaria and non-malaria case outcomes.

Figure 4

Footnote: Information on net deliveries was assembled from a variety of sources for each district. We assumed that ITN coverage was less than 5\% between January 1999 and December 2002. This position is supported by reviews of net use undertaken in Kenya during this period [34]. In Kilifi district a large scale trial of ITN was completed in 1993 [35] and by 1997 there were few net replacements or net re-treatments [36]. From 2002 Population Services International (PSI) had launched a retail sector, social marketing campaign for ITN distribution [37]. Annual sales figures for the coast were obtained from PSI for the period January 2002 through to December 2004. Toward the end of 2004 PSI delivered heavily subsidized ITN through clinics and monthly sales by geopositioned clinics in each of the three districts were available for the period November 2004 to March 2007. In September 2006 the Ministry of Health launched a largescale free distribution campaign of free ITN to children under the age of five years [4]. Net distribution volumes were recorded per geo-located distribution point within each district. Finally, small-scale community distribution projects over the surveillance by the district heath management team, NGO's and philanthropic organizations were recorded through interviews with DHMT members 
and district stakeholders and recorded as volumes of distribution and month of delivery. Cumulative monthly ITN distribution volumes per district were computed per capita using population size estimates derived from national census data and annual growth rates. This was implemented with projected population growth rate curves from national inter-censal district-specific annual rates of net population increase derived in 1989 and 1999 [38].

\section{Acknowledgements}

This study received financial support from The Wellcome Trust, UK (\#058922), the British Department for International Development Kenya Programme (\#KEN/2004/085), Ministry of Health, Government of Kenya (DFID agreement number \#AF/06/4I6254) and The Kenyan Medical Research Institute. RWS is supported by the Wellcome Trust as Principal Research Fellow (\#07908I). We are indebted to the medical records officers in Kwale and Malindi: Katana Ndegwa, Joseph Rimba, Priscilla Folonzi and Ambrose Munga for their help with assembling data from these hospitals. The invaluable support provided by Drs James Nokes, Jay Berkley, Antony Scott, Charles Newton and Evasius Bauni at the KEMRI programme in Kilifi for maintaining the long-term hospital surveillance. We also wish to thank Dr Willis Akhwale of the Ministry for Health, Veronica Musembi of PSI-Kenya, and Samuel Waweru of the Metrological department for their assistance in obtaining various data sets. We are grateful to Wendy Omeara for her comments on earlier versions of the manuscript. This paper is published with the permission of the Director KEMRI.

\section{References}

I. Nabarro DN, Tayler EM: The "roll back malaria" campaign. Science 1998, 280:2067-2068.

2. World Malaria Report 2005. Geneva, Switzerland: Prepared by Roll Back Malaria, World Health Organization and United Nations Children Fund .

3. Snow RW, Craig M, Deichmann U, Marsh K: Estimating mortality, morbidity and disability due to malaria among Africa's nonpregnant population. Bull World Health Organ 1999, 77:624-640.

4. Noor AM, Amin AA, Akhwale WS, Snow RW: Increasing coverage and decreasing inequity in insecticide-treated bed net use among rural Kenyan children. PLoS Med 2007, 4:e255.

5. Amin AA, Zurovac D, Kangwana BB, Greenfield J, Otieno DN, Akhwale WS, Snow RW: The challenges of changing national malaria drug policy to artemisinin-based combinations in Kenya. Malar J 2007, 6:72.

6. Zurovac D, Ngigi J, Akhwale WS, Hamer DH, Snow RW: Translation of artemether-lumefathrine paediatric malaria treatment policy into clinical practice: the example of Kenya. Trop Med Int Health, under review.

7. English M, Esamai F, Wasunna A, Were F, Ogutu B, Wamae A, Snow RW, Peshu N: Assessment of inpatient paediatric care in first referral level hospitals in 13 districts in Kenya. Lancet 2004, 363:1948-1953.

8. Font F, Alonso Gonzalez M, Nathan R, Kimario J, Lwilla F, Ascaso C, Tanner M, Menendez C, Alonso PL: Diagnostic accuracy and case management of clinical malaria in the primary health services of a rural area in south-eastern Tanzania. Trop Med Int Health 200I, 6:423-428.

9. Reyburn H, Mbatia R, Drakeley C, Carneiro I, Mwakasungula E, Mwerinde O, Saganda K, Shao J, Kitua A, Olomi R, Greenwood BM, Whitty $\mathrm{CJ}$ : Overdiagnosis of malaria in patients with severe febrile illness in Tanzania: a prospective study. Bmj 2004, 329:1212.

10. Zurovac D, Media B, English M, Ochola SA, Snow RW: Current and potential effects of microscopy on outpatient malaria case management among older children and adults in Kenya. Trop Med Int Health 2006, I I:432-440.

II. Berkley J, Mwangi I, Griffiths K, Ahmed I, Mithwani S, English M, Newton C, Maitland K: Assessment of severe malnutrition among hospitalized children in rural Kenya: comparison of weight for height and mid upper arm circumference. Jama 2005, 294:59|-597.

12. Berkley JA, Lowe BS, Mwangi I, Williams T, Bauni E, Mwarumba S, Ngetsa C, Slack MP, Njenga S, Hart CA, Maitland K, English M, Marsh K, Scott JA: Bacteremia among children admitted to a rural hospital in Kenya. N Engl J Med 2005, 352:39-47.

13. English M, Ngama M, Musumba C, Wamola B, Bwika J, Mohammed S, Ahmed M, Mwarumba S, Ouma B, McHugh K, Newton C: Causes and outcome of young infant admissions to a Kenyan district hospital. Arch Dis Child 2003, 88:438-443.

14. Snow RW, Howard SC, Mung'Ala-Odera V, English M, Molyneux CS, Waruiru C, Mwangi I, Roberts DJ, Donnelly CA, Marsh K: Paediatric survival and re-admission risks following hospitalization on the Kenyan coast. Trop Med Int Health 2000, 5:377-383.

15. Snow RW, Schellenberg JR, Peshu N, Forster D, Newton CR, Winstanley PA, Mwangi I, Waruiru C, Warn PA, Newbold C, Marsh K: Periodicity and space-time clustering of severe childhood malaria on the coast of Kenya. Trans R Soc Trop Med Hyg 1993, 87:386-390.

16. Mbogo CM, Mwangangi JM, Nzovu J, Gu W, Yan G, Gunter JT, Swalm C, Keating J, Regens JL, Shililu JI, Githure JI, Beier JC: Spatial and temporal heterogeneity of Anopheles mosquitoes and Plasmodium falciparum transmission along the Kenyan coast. Am J Trop Med Hyg 2003, 68:734-742.

17. Noor AM, Amin AA, Gething PW, Atkinson PM, Hay SI, Snow RW: Modelling distances travelled to government health services in Kenya. Trop Med Int Health 2006, I I: 188-196.

18. Altman D: Practical statistics for medical research. Boca Raton (Florida): Chapman \& Hall/CRC; 1999.

19. Chatfield $C$, (Ed.): The analysis of time series. An introduction. 4th edition. London: Chapman and Hall; 1989.

20. Durbin J, Watson GS: Testing for serial correlation in least squares regression. II. Biometrika 195I, 38:159-178.

21. StataCorp: Time-Series Texas: StataCorp; 2005

22. Newey W, West K: A simple, positive semidefinite, heteroskedasticity and autocorreltion consistent covariance matrix. Econometrica 1987, 55:703-708.

23. Habicht JP, Victora CG, Vaughan JP: Evaluation designs for adequacy, plausibility and probability of public health programme performance and impact. Int J Epidemiol 1999, 28:10-18.

24. Victora CG, Habicht JP, Bryce J: Evidence-based public health: moving beyond randomized trials. Am J Public Health 2004, 94:400-405.

25. Shretta R, Omumbo J, Rapuoda B, Snow RW: Using evidence to change antimalarial drug policy in Kenya. Trop Med Int Health 2000, 5:755-764.

26. The efficacy of antimalarial monotherapies, sulphadoxinepyrimethamine and amodiaquine in East Africa: implications for sub-regional policy. Trop Med Int Health 2003, 8:860-867.

27. Ogutu BR, Nzila AM, Ochong E, Mithwani S, Wamola B, Olola CH, Lowe B, Kokwaro GO, Marsh K, Newton CR: The role of sequential administration of sulphadoxine/pyrimethamine following quinine in the treatment of severe falciparum malaria in children. Trop Med Int Health 2005, 1 0:484-488.

28. Falade C, Makanga M, Premji Z, Ortmann CE, Stockmeyer M, de Palacios PI: Efficacy and safety of artemether-lumefantrine (Coartem) tablets (six-dose regimen) in African infants and children with acute, uncomplicated falciparum malaria. Trans R Soc Trop Med Hyg 2005, 99:459-467.

29. Amin AA, Marsh V, Noor AM, Ochola SA, Snow RW: The use of formal and informal curative services in the management of paediatric fevers in four districts in Kenya. Trop Med Int Health 2003, 8: II43-II52.

30. Abuya TO, Mutemi W, Karisa B, Ochola SA, Fegan G, Marsh V: Use of over-the-counter malaria medicines in children and adults in three districts in Kenya: implications for private medicine retailer interventions. Malar $J$ 2007, 6:57.

3I. Amin AA, Hughes DA, Marsh V, Abuya TO, Kokwaro GO, Winstanley PA, Ochola SA, Snow RW: The difference between effectiveness and efficacy of antimalarial drugs in Kenya. Trop Med Int Health 2004, 9:967-974.

32. Marsh VM, Mutemi WM, Willetts A, Bayah K, Were S, Ross A, Marsh $\mathrm{K}$ : Improving malaria home treatment by training drug retailers in rural Kenya. Trop Med Int Health 2004, 9:45 I-460. 
33. Schellenberg D, Cisse B, Menendez C: The IPTi Consortium: research for policy and action. Trends Parasitol 2006, 22:296-300.

34. Shretta R: NETMARK Briefing Book : Insecticide Treated materials in Kenya. Malaria Consortium, UK, for Academy for Educational Development; 1999.

35. Nevill CG, Some ES, Mung'ala VO, Mutemi W, New L, Marsh K, Lengeler C, Snow RW: Insecticide-treated bednets reduce mortality and severe morbidity from malaria among children on the Kenyan coast. Trop Med Int Health 1996, I:I39- I 46.

36. Snow RW, McCabe E, Mbogo CN, Molyneux CS, Some ES, Mung'ala VO, Nevill CG: The effect of delivery mechanisms on the uptake of bed net re-impregnation in Kilifi District, Kenya. Health Policy Plan 1999, 14:18-25.

37. Noor AM, Omumbo JA, Amin AA, Zurovac D, Snow RW: Wealth, mother's education and physical access as determinants of retail sector net use in rural Kenya. Malar J 2006, 5:5.

38. Central Bureau of Statistics: 1999 population and housing census: counting our people for development. Volume 2: Socioeconomic profile of the people. Volume 2. Central Bureau of Statistics : Ministry of Finance \& Planning, GoK; 200I.

Publish with Bio Med Central and every scientist can read your work free of charge

"BioMed Central will be the most significant development for disseminating the results of biomedical research in our lifetime. "

Sir Paul Nurse, Cancer Research UK

Your research papers will be:

- available free of charge to the entire biomedical community

- peer reviewed and published immediately upon acceptance

- cited in PubMed and archived on PubMed Central

- yours - you keep the copyright

Submit your manuscript here:

http://www.biomedcentral.com/info/publishing_adv.asp
BioMedcentral 